\title{
A novel mechanism in control of human pigmentation by $\beta$-melanocyte-stimulating hormone and 7-tetrahydrobiopterin
}

\author{
Jennifer D Spencer ${ }^{1}$, Bhaven Chavan ${ }^{1}$, Lee K Marles ${ }^{1}$, \\ Sobia Kauser ${ }^{3}$, Hartmut Rokos ${ }^{2}$ and Karin U Schallreuter ${ }^{1,2}$ \\ ${ }^{1}$ Clinical and Experimental Dermatology, Department of Biomedical Sciences, University of Bradford, Bradford BD7 1DP, UK \\ ${ }^{2}$ Institute for Pigmentary Disorders in association with EM Arndt University Greifswald, Germany and University of Bradford, Bradford BD7 1DP, UK \\ ${ }^{3}$ Biomedical Sciences, University of Bradford, Bradford BD7 1DP, UK \\ (Requests for offprints should be addressed to K U Schallreuter; Email: K.Schallreuter@bradford.ac.uk)
}

\begin{abstract}
The human skin holds the full machinery for proopiomelanocortin processing. The $\alpha$-melanocytestimulating hormone $(\alpha-\mathrm{MSH}) /$ melanocortin-1-receptor cascade has been implicated as a major player via the cAMP signal in the control of melanogenesis. Only very recently the $\beta$-endorphin/ $\mu$-opiate receptor signal has been added to the list of regulators of melanocyte dendricity and melanin formation. In this context it was reported that (6R)-L-erythro-5,6,7,8-tetrahydrobiopterin $\left(6 \mathrm{BH}_{4}\right)$ can act as an allosteric inhibitor of tyrosinase, the key enzyme in melanogenesis, and this inhibition is reversible by both $\alpha$ - and $\beta-\mathrm{MSH}$. It was also shown earlier that $7 \mathrm{BH}_{4}$, the isomer of $6 \mathrm{BH}_{4}$, is twice as active in this inhibition reaction. However, as yet it is not known
\end{abstract}

whether $7 \mathrm{BH}_{4}$ is indeed present in loco in the melanosome. We here provide evidence that this isomer is present in this organelle in a concentration range up to $50 \times 10^{-6} \mathrm{M}$. Determination of $\beta-\mathrm{MSH}$ in melanosomal extracts yielded $10 \mathrm{pg} / \mathrm{mg}$ protein. Moreover, we demonstrate reactivation of the $7 \mathrm{BH}_{4} /$ tyrosinase inhibitor complex by $\beta-\mathrm{MSH}$, whereas $\alpha-\mathrm{MSH}$ failed to do so. Furthermore, we show intra-melanosomal L-dopa formation from dopachrome by $7 \mathrm{BH}_{4}$ in a concentration range up to $134 \times 10^{-6} \mathrm{M}$. Based on these results, we propose a new receptorindependent mechanism in the control of tyrosinase/ melanogenesis by $\beta-\mathrm{MSH}$ and the pterin $7 \mathrm{BH}_{4}$.

Journal of Endocrinology (2005) 187, 293-302

\section{Introduction}

Today there is compelling evidence that proopiomelanocortin (POMC) peptides are implicated in the regulation of skin colour in humans (Abdel-Malek et al. 1995). Moreover, it has been shown that the skin and the hair follicle are the local sources and targets for POMCderived peptides including adrenocorticotrophin (ACTH), $\alpha$ - and $\beta$-melanocyte-stimulating hormone (MSH) and $\beta$-endorphin (Thody et al. 1983, Tsatmali et al. 1999, 2000, Kauser et al. 2003, 2005). The involvement of ACTH, and of $\alpha$ - and $\beta-\mathrm{MSH}$ in human skin pigmentation was first recognised upon systemic application into human volunteers where these peptides induced noticeable skin darkening (Lerner \& McGuire 1961, 1964, Geschwind et al. 1972). Later, it was shown that ACTH, $\alpha-\mathrm{MSH}$ and $\beta$-endorphin could stimulate melanogenesis and proliferation of epidermal and hair follicle melanocytes and modulate cell dendricity (Hunt et al. 1994, Abdel-Malek et al. 1995, Kauser et al. 2003, 2005). Both $\alpha-\mathrm{MSH}$ and ACTH are proposed to be the key players in pigmentation via the melanocortin-1-receptor (MC1-R)/ cAMP second messenger system (Tsatmali et al. 1999,
2000). Moreover, it was shown that $\beta$-MSH stimulates changes in melanocyte morphology, growth rates and melanin production (McLane \& Pawelek 1988, Chakraborty et al. 1991). However, its mode of action is still not completely understood. Since the presence of both $\alpha-\mathrm{MSH}$ and $\beta$-endorphin together with the complete POMC processing machinery, including prohormone convertases 1/2 (PC1, PC2) and 7B2, have been demonstrated inside the melanosome of epidermal and hair follicle melanocytes, it was expected that $\beta-\mathrm{MSH}$ is also present in this organelle (Peters et al. 2000, Kauser et al. 2003). In this context a receptor-independent stimulation of tyrosinase (EC $1 \cdot 14 \cdot 18 \cdot 1)$ by $\alpha-\mathrm{MSH}$ has been suggested where this peptide reacts as an activator of the (6R)-L-erythro-5,6,7,8-tetrahydrobiopterin $\left(6 \mathrm{BH}_{4}\right) /$ tyrosinase inhibitor complex (Schallreuter et al. 1999, Peters et al. 2000). Here, it is noteworthy that epidermal melanocytes have the full capacity for autocrine de novo synthesis/recycling/regulation of $6 \mathrm{BH}_{4}$ which, in turn, is mandatory for intracellular L-phenylalanine and L-tyrosine turnover via phenylalanine hydroxylase (EC 1·14.16.1; $\mathrm{PAH}$ ) and tyrosine hydroxylase (EC $1 \cdot 14 \cdot 16 \cdot 2 ; \mathrm{TH}$ ) respectively (Schallreuter et al. 1994b). The recycling of 
$6 \mathrm{BH}_{4}$ is under the control of pterin-4a-carbinolamine dehydratase (EC 4.2.1.96; PCD) and dihydropteridine reductase (EC 1.6.99.7; DHPR) (Thöny et al. 2000). In the absence of a functionally active PCD enzyme, the 7-isomer of $6 \mathrm{BH}_{4}$ is formed from non-enzymatic re-arrangement of the intermediate $4 \mathrm{a}$-carbinolamine (Curtius et al. 1990a,b, Davis \& Kaufman 1991, Davis et al. 1992). Elevated levels of $7 \mathrm{BH}_{4}$ were first described by Curtius and colleagues in patients with a variant form of phenylketonuria (Curtius et al. 1988, 1990b). Later, this accumulation was explained by a mutation in the PCD gene (Adler et al. 1992). High 7 $\mathrm{BH}_{4}$ levels were also found in the epidermis of patients with the depigmentation disorder, vitiligo (Schallreuter et al. 1994a,b). In the latter case, it was shown that these high levels are based on deactivation of the enzyme PCD due to accumulation of $\mathrm{H}_{2} \mathrm{O}_{2}$ in the $10^{-3} \mathrm{M}$ range (Schallreuter et al. 2001).

'Taken together, a role for $7 \mathrm{BH}_{4}$ in the pathophysiology of these two diseases has been proved. However, to the best of our knowledge a physiological role for this isomer has never been documented.

Earlier in vitro studies reported that $7 \mathrm{BH}_{4}$ is a potent competitive inhibitor of PAH (Curtius et al. 1990a,b, Davis et al. 1992), whereas this isomer was a potent uncompetitive inhibitor of tyrosinase (Wood et al. 1995). In fact it was shown that $7 \mathrm{BH}_{4}$ was twice as potent at inhibiting tyrosinase activity compared with $6 \mathrm{BH}_{4}$ (Wood et al. 1995). Unlike the activation of the $6 \mathrm{BH}_{4} /$ tyrosinase inhibitor complex by $\alpha-\mathrm{MSH}, 7 \mathrm{BH}_{4}$ cannot be removed from its inhibitor complex by this peptide (Moore et al. 1999, Schallreuter et al. 1999).

Since $\beta-\mathrm{MSH}$ can also activate the $6 \mathrm{BH}_{4} /$ tyrosinase inhibitor complex under in vitro conditions (Marles et al. 2002), we asked the question whether this peptide has the capacity to bind $7 \mathrm{BH}_{4}$ from its inhibitor complex. In order to substantiate this hypothesis, it was mandatory to show the presence and functionality of $\beta-\mathrm{MSH}$ and $7 \mathrm{BH}_{4}$ in melanocytes and in its specific organelle, the melanosome. Therefore, we applied various in situ and in vitro techniques: immunofluorescence labelling, immunogoldelectron microscopy, Western blot analyses, radioimmunoassay, enzyme kinetics and HPLC analysis. Our data demonstrate that $\beta-\mathrm{MSH}$ is present in keratinocytes and in melanocytes and that both $\beta-\mathrm{MSH}$ and $7 \mathrm{BH}_{4}$ are found in the melanosome. Based on these results we propose that $7 \mathrm{BH}_{4}$ can regulate human melanogenesis via $\beta-\mathrm{MSH}$ by a receptor-independent mechanism. Moreover, our observation suggests, for the first time, a physiological function for the 7-isomer of $6 \mathrm{BH}_{4}$.

\section{Materials and Methods}

\section{Cell culture}

Individual epidermal melanocytes and keratinocytes were established from 3 different healthy donors (skin phototype
III, Fitzpatrick classification) (Fitzpatrick et al. 1967) obtained after informed consent from plastic surgery $(n=1)$ or alternatively from suction blister roofs $(n=2)$ using the method of Kiistala and Mustakallio (1964). This study was approved by the local Ethics committee and was in agreement with the principles of the Helsinki declaration.

The human melanoma cell lines FM55 and FM94 and murine B16 melanoma cells were cultured in RPMI 1640 (Gibco Invitrogen, Paisley, Strathclyde, UK) medium containing 10\% FBS (Gibco Invitrogen) and 1\% penicillin/ streptomycin (Gibco Invitrogen). Cell lines required a change of medium every 1-2 days. Cultures were passaged after the population reached $70-80 \%$ confluence.

In situ and in vitro immunofluorescence labelling of $\beta$-MSH in melanocytes

Normal human skin from five different healthy donors (skin phototype III, Fitzpatrick classification) (Fitzpatrick et al. 1967) was obtained via $3-\mathrm{mm}$ punch biopsies and mounted using OCT embedding medium (Raymond A Lamb, Eastbourne, East Sussex, UK). Cryosections, $5 \mu \mathrm{m}$ thick, were cut onto poly-L-lysine (Sigma, Poole, Dorset, UK)-coated slides. The slides were air-dried at room temperature and fixed in ice-cold acetone for $10 \mathrm{~min}$ at $-20^{\circ} \mathrm{C}$ and rehydrated in PBS for $5 \mathrm{~min}$.

Sections were blocked in 10\% normal donkey serum (NDS) in PBS for 90 min at room temperature and rinsed briefly in PBS. This was followed by incubation with the first primary melanocyte/melanosome antibody NKI/ beteb (gp100) (Monosan, Bradsure Biologics Ltd, Loughborough, Leics, UK) diluted 1:20 in 1\% NDS, for $18 \mathrm{~h}$ at $4{ }^{\circ} \mathrm{C}$. After washing 4 times in PBS for $20 \mathrm{~min}$, the sections were incubated with a fluorescein-conjugated donkey anti-mouse secondary antibody (Jackson Immunoresearch Laboratories, Inc., Pennsylvania, PA, USA) at a dilution of 1:100 with 1\% NDS, for $1 \mathrm{~h}$ at room temperature. Following incubation, sections were washed as before and blocked with 10\% NDS at room temperature for $1 \mathrm{~h}$. After a brief rinse in PBS, sections were incubated with the second primary $\beta$-MSH polyclonal antibody (Bachem Ltd, St. Helens, Merseyside, UK), diluted 1:200, for $2 \mathrm{~h}$ at room temperature, followed by subsequent washing. A rhodamine-conjugated donkey anti-rabbit antibody (Jackson Immunoresearch Laboratories, Inc.) was added at a dilution of 1:100, and left for incubation at room temperature for $1 \mathrm{~h}$. After a final wash, sections were carefully dried and mounted in Vectashield mounting medium containing DAPI (Vector Laboratories Ltd, Peterborough, UK).

Sections were viewed with a Leica DMIRB/E fluorescence microscope (Wetzlar, Germany) and photodocumented using a computer-assisted 3-CCD colour video camera and the Image Grabber PCI graphics program (both from Optivision, Osset, West Yorkshire, UK). For staining of cultured epidermal melanocytes, cells 
were seeded into 8-well Laboratory-Tek chamber slides (ICN Biomedicals, Inc., Costa Mesa, OH, USA) and allowed to attach. Before fixation in ice-cold methanol for 10 min at $-20{ }^{\circ} \mathrm{C}$, cells were rinsed briefly in PBS. The staining procedure was followed as described above with cells incubated for $2 \mathrm{~h}$ at room temperature with $\beta-\mathrm{MSH}$ at a dilution of 1:100.

\section{Immunogold transmission electron microscopy for detection of $\beta-\mathrm{MSH}$ in melanosomes}

Epidermal melanocytes (passages 3-5) were harvested by trypsin exposure. The cells were centrifuged at a low speed and the cell pellet fixed in $0.5 \%$ glutaraldehyde (Agar Scientific, Stanstead, Essex, UK), 2\% paraformaldehyde (Sigma) in $0.1 \mathrm{M}$ sodium cacodylate buffer (Sigma) containing $0 \cdot 027 \mathrm{mM} \mathrm{CaCl}_{2}$ (Sigma), buffered to $\mathrm{pH} 7 \cdot 4$, for $1 \mathrm{~h}$ at room temperature. After fixation, cells were washed in PBS for $25 \mathrm{~min}$ and rinsed with $0.1 \mathrm{M}$ glycine in PBS for $5 \mathrm{~min}$. The cells were pelleted through low melting point agarose (Bio-Rad Laboratories, Hercules, CA, USA) and allowed to cool down before cutting into $1-\mathrm{mm}$ small pieces. These were fixed in $3 \%$ osmium tetraoxide $(90 \mathrm{~min})$, dehydrated in graded series of ethanol and infiltrated with hydrophilic Unicryl resin (British BioCell International, Cardiff, Wales, UK), finally followed by polymerisation with UV radiation $(360 \mathrm{~nm})$ at $4{ }^{\circ} \mathrm{C}$ for $72 \mathrm{~h}$.

Using a Reichert-Jung ultramicrotome (Vienna, Austria), ultrathin sections were cut and mounted on 200 mesh carbon-coated nickel grids (Agar Scientific).

Sections processed as above were blocked for $1 \mathrm{~h}$ in $10 \%$ normal goat serum and 2\% BSA in PBS, $\mathrm{pH} 8 \cdot 2(1 \%$ normal goat serum in the same blocking buffer was used to dilute the primary and secondary antibodies). The sections were washed twice in PBS containing 2\% BSA ( $\mathrm{pH} 8 \cdot 2$ ) and incubated with polyclonal anti-human $\beta-\mathrm{MSH}$ (Bachem Ltd) primary antibody at a dilution of 1:200 for $18 \mathrm{~h}$ at $4{ }^{\circ} \mathrm{C}$. Following incubation, the sections were washed in $2 \%$ BSA/PBS ( $\mathrm{pH} 8.2$ ) and incubated in a 1:60 dilution of the secondary goat anti-rabbit antibody conjugated to $10 \mathrm{~nm}$ gold particles (British BioCell International) for $1 \mathrm{~h}$ at room temperature. Following a final wash in distilled water, the sections were lightly counterstained with 2\% Uranyl acetate and Reynold's lead citrate solution and examined and photographed using a JEM-1200 EX transmission electron microscope (Jeol Tokyo, Japan).

\section{Western blot analysis}

Normal human epidermal primary keratinocytes and melanocytes were harvested in the presence of a protease inhibitor cocktail (Sigma) at concentrations recommended by the manufacturer. Purified melanosomes from FM55 and FM94 melanoma cells underwent the same procedure. Cell/melanosome lysis was achieved by 6 freeze-thawing cycles followed by centrifugation at 1200 r.p.m. for 5 min. The supernatant was separated in 12\% SDS-PAGE and proteins transferred to a PDF membrane (Immobilon, Millipore, Bedford, Beds, UK). The membrane was blocked with $3 \%$ BSA in TBS-T buffer $(20 \mathrm{mM}$ Tris buffered saline with $0.047 \%$ Tween at $\mathrm{pH} 7 \cdot 4$ ) and incubated for $2 \mathrm{~h}$ with a polyclonal rabbit anti- $\beta-\mathrm{MSH}$ antibody (dilution 1:1000, Bachem Ltd). The blot was washed and incubated for $1 \mathrm{~h}$ with an anti-rabbit immunoglobulin $\mathrm{G}(\mathrm{IgG})$ peroxidase-conjugated antibody (Fc specific, dilution 1:5000, Sigma). Visualisation of the bands was performed using modified enhanced chemiluminescence (ECL) fixed on a film sheet (X-OMAT, Kodak, USA).

\section{Sucrose density gradient purification of melanosomes from cultured melanoma cells}

In order to get the necessary quantities for the experiments, melanosomes were purified from human melanoma cells (FM55, FM94) and from murine B16 melanoma cells using the method described by Seiji et al. (1961). Briefly, a cellular homogenate is processed by centrifugation to provide a suspension of the large molecular weight organelles (mitochondria and melanosomes). In the second step, these organelles are separated on a sucrose gradient by ultracentrifugation allowing isolation of purified melanosomes of all maturation stages. Purified melanosomes were lysed via a repeated freeze/thaw cycle to obtain the melanosomal extract. The purity of the final preparation was examined by electron microscopy.

\section{Protein determination}

Total protein concentrations of melanosomal extracts were determined spectrophotometrically at $280 \mathrm{~nm}$ with a Beckman DU-64 UV spectrophotometer as described by Kalb and Bernlohr (1977).

\section{Determination of $\beta$-MSH by radioimmunoassay}

Melanosomal extracts were prepared as described above. $\beta-\mathrm{MSH}$ concentrations were determined in duplicate using a commercial radioimmunoassay kit for the peptide (Peninsula Laboratories, Inc. Division of Bachem, Torrance, CA, USA) following the manufacturer's protocol. This antibody does not cross-react with $\alpha$-MSH or $\beta$-lipotrophin according to the manufacturer. The results were based on a $\beta-\mathrm{MSH}$ standard curve, which was determined at the same time and together with the samples.

\section{Pterin analysis of melanosomal extracts by HPLC}

Pterin analysis was based on the established HPLC method described by Ziegler and Hültner (1992). Briefly, purified 
melanosomes from human melanoma cells were obtained as described and were immediately re-suspended in $0.05 \mathrm{M}$ Tris- $\mathrm{HCl}(\mathrm{pH} 7 \cdot 5)$ and snap frozen in liquid nitrogen. Extracts were made by grinding frozen preparations in a pre-cooled micro-pestle and mortar followed by centrifugation at $700 \mathrm{~g}$ for $5 \mathrm{~min}$. In order to determine the pterin content in melanosomes, melanosomal extracts were oxidised under acidic conditions, followed by separation of the pterins with DOWEX (BioRAD, Hemel Hempstead, Herts, UK).

HPLC analysis was conducted on a Dynamax SD-300 instrument with a $25 \mathrm{~cm} \mathrm{C}-18$ reverse-phase column (Sphereclone $5 \mu \mathrm{M}$ ODS1, Phenomenex, Macclesfield, Cheshire, UK) maintained at $22{ }^{\circ} \mathrm{C}$, coupled to a Shimadzu RF-535 fluorescence detector $\left(\lambda_{\mathrm{EX}} 350 \mathrm{~nm}\right.$, $\lambda_{\text {EM }} 450 \mathrm{~nm}$ ) interfaced with a computer and Dynamax PC version 1.6 software. For pterin analysis a filtered acidic mobile phase buffer was used (1\% acetonitrile, $2 \%$ methanol and $1 \times 10^{-3} \mathrm{M} \mathrm{H}_{3} \mathrm{PO}_{4}$ in HPLC grade water (Fisher Chemicals, Loughborough, Leics, UK)). The flow rate was maintained at $1.0 \mathrm{ml} / \mathrm{min}$ and $100 \mu \mathrm{l}$ melanosomal extract were injected per analysis in the presence or absence of $1 \mu \mathrm{M}$ 7-biopterin standard. Experiments were carried out in duplicates.

\section{$\left.{ }^{3} \mathrm{H}\right] 6 \mathrm{BH}_{4}$ uptake in purified melanosomes}

In order to follow possible uptake of cytosolic $6 \mathrm{BH}_{4}$ into melanosomes, preparations of intact melanosomes from B16 melanoma cells were resuspended in PBS containing $0.5 \mathrm{M}$ dithiothreitol (DTT), $\mathrm{pH} 7 \cdot 4$. For each assay $700 \mu \mathrm{g}$ melanosomal protein were mixed with $10 \mu \mathrm{l} 0.75 \mathrm{mM}$ unlabelled (cold) $6 \mathrm{BH}_{4}$ (Schircks Laboratories, Jona, Switzerland) and $15 \mu \mathrm{l}(33 \mathrm{KBqs})\left[{ }^{3} \mathrm{H}\right] 6 \mathrm{BH}_{4}(20 \mathrm{Ci} /$ mmol, $2.9 \mu \mathrm{mol} / \mathrm{l}$ ) in a final reaction volume of $75 \mu \mathrm{l}$ PBS/DTT buffer. Reactions were mixed and incubated at $37^{\circ} \mathrm{C}$ over time (5-15-25-35 min). Immediately following incubation, the melanosomes were centrifuged at 1200 r.p.m. for $5 \mathrm{~min}$ at $4{ }^{\circ} \mathrm{C}$ followed by a gentle wash of the pellet in $500 \mu \mathrm{lBS} / \mathrm{DTT}$ buffer, and centrifugation. This step was repeated 3 times. In order to ensure that the washing procedure cleaned all free radiolabel, $50 \mu \mathrm{l}$ of the last supernatant was counted in $4 \mathrm{ml}$ scintillation cocktail (Ready-Safe Liquid Scintillation cocktail, Beckman, Fullerton, CA, USA) in the ${ }^{3} \mathrm{H}$ channel in a Wallac1209 Rackbeta liquid scintillation counter. The uptake of the ${ }^{3} \mathrm{H}$-labelled $6 \mathrm{BH}_{4}$ into the melanosomes was determined in the pellet after the fourth wash at each time point. Before counting, the pellet was re-suspended in $100 \mu \mathrm{l}$ PBS/DTT buffer. ${ }^{3} \mathrm{H}$-labelled $6 \mathrm{BH}_{4}$ was a kind gift from E Werner, University of Innsbruck, Austria.

\section{Inhibition of mushroom tyrosinase by $7 \mathrm{BH}_{4}$}

Mushroom tyrosinase was obtained from Sigma and $7 \mathrm{BH}_{4}$ was from Schircks Laboratories. Tyrosinase activities were measured by following the formation of dopachrome at $475 \mathrm{~nm}$. All reactions were performed in $0 \cdot 1 \mathrm{M} \mathrm{KH}_{2} \mathrm{PO}_{4}$ buffer at $\mathrm{pH} 7 \cdot 4$ and reaction rates were determined in the linear phase by measuring $\Delta \mathrm{OD}_{475} / 2 \mathrm{~min}$. The inhibition of tyrosinase by $7 \mathrm{BH}_{4}$ was determined over a concentration range of $0-0 \cdot 45 \times 10^{-3} \mathrm{M}$ to confirm the previously established $K_{\mathrm{i}}$ value (Wood et al. 1995). V vs S (V, velocity; S, substrate concentration) results were compared with the control values without the addition of inhibitor in the presence of different concentrations of the substrate L-tyrosine $\left(0-3 \times 10^{-3} \mathrm{M}\right)$. Lineweaver-Burk plots were obtained from the $\mathrm{V}$ vs $\mathrm{S}$ data to ascertain the inhibitor mechanism.

\section{Reactivation of the tyrosinase $/ 7 \mathrm{BH}_{4}$ inhibitor complex by $\beta-M S H$}

Following the dopachrome formation at $475 \mathrm{~nm} / \mathrm{min}$, the standard tyrosinase reaction was allowed to reach linear kinetics (at $4.5 \mathrm{~min}$ ) before $7 \mathrm{BH}_{4}$ was added to completely inhibit the reaction. The chosen concentration of $7 \mathrm{BH}_{4}$ was $65 \mu \mathrm{M}$ based on the $K_{\mathrm{i}}$ value. At $6.5 \mathrm{~min} 10 \mu \mathrm{M}$ $\beta$-MSH were added to reactivate the enzyme. After the $\beta-\mathrm{MSH}$ bound $7 \mathrm{BH}_{4}$, the enzyme was again inhibited by the remaining $7 \mathrm{BH}_{4}$ in the reaction mixture. Reactivation was achieved upon addition of a further $10 \mu \mathrm{M} \beta-\mathrm{MSH}$.

\section{Reduction of dopachrome to L-dopa in the presence of $7 \mathrm{BH}_{4}$}

The formation of dopachrome from L-tyrosine, by tyrosinase, at a $\mathrm{pH}$ of $7 \cdot 4$ was followed in the presence and absence of $7 \mathrm{BH}_{4}\left(0-134 \times 10^{-6} \mathrm{M}\right)$. The observed reduction of dopachrome to L-dopa was subsequently examined via HPLC analysis as previously described, with the fluorescence detector at $\lambda_{\mathrm{EX}} 280 \mathrm{~nm} \lambda_{\mathrm{EM}} 320 \mathrm{~nm}$. The mobile phase was methanol:heptanesulphonic acid buffer $(2 \cdot 5: 32(\mathrm{v} / \mathrm{v}))$ and the flow rate was maintained at $1.0 \mathrm{ml} /$ min. L-Dopa standards were prepared as $1 \mathrm{mM}$ stock solutions and L-tyrosine standards were prepared as $10 \mathrm{mM}$ stock solutions, $\mathrm{pH} 9 \cdot 2$. The optimum concentration for dopachrome reduction was $134 \mu \mathrm{M} 7 \mathrm{BH}_{4}$. Samples were taken every 2 min from the standard tyrosinase reaction mixture in the presence and absence of $7 \mathrm{BH}_{4}$. Samples were immediately diluted 1:10 with heptanesulphonic acid buffer and kept on ice. Twenty microlitres of the diluted sample were injected per analysis, with or without appropriate addition of standards. Internal controls included the analysis of the reaction mixture in the absence of $7 \mathrm{BH}_{4}$ and tyrosinase. In order to compare the reduction of dopachrome between $6 \mathrm{BH}_{4}$ and $7 \mathrm{BH}_{4}$, reactions were followed upon addition of $0-134 \mu \mathrm{M}$ $6 \mathrm{BH}_{4}$. Experiments were carried out in duplicate.

\section{Detection of L-dopa in melanosomes by HPLC}

Purified melanosomes were immediately resuspended in $100 \mu \mathrm{l}$ heptanesulphonic acid buffer $\mathrm{pH} 4 \cdot 0\left(6 \times 10^{-3} \mathrm{M}\right.$ 

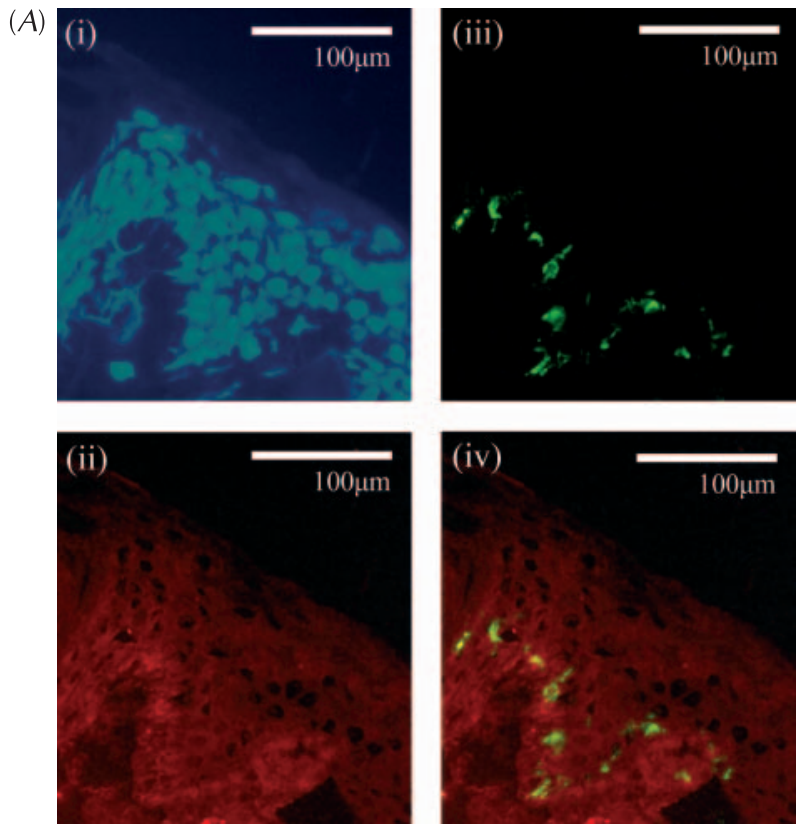

(C)
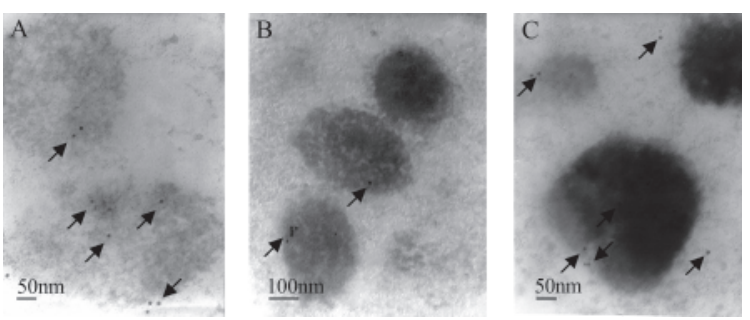

(B)
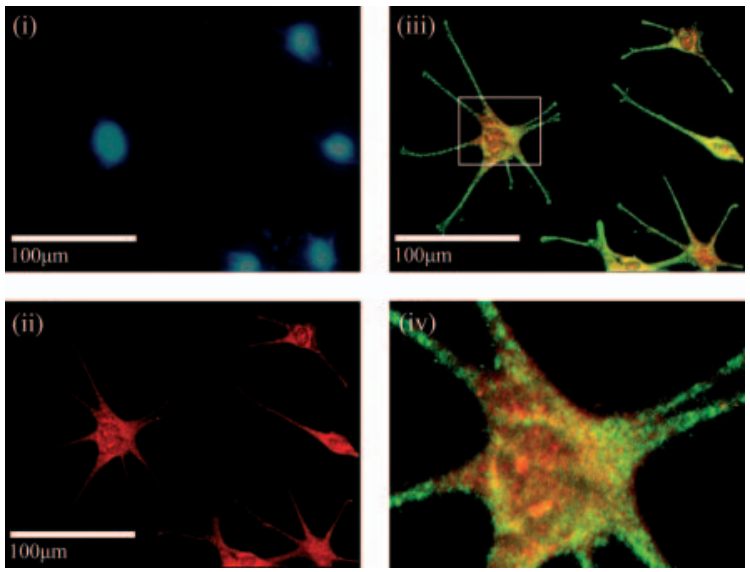

(D) $20 \mathrm{kDa}$
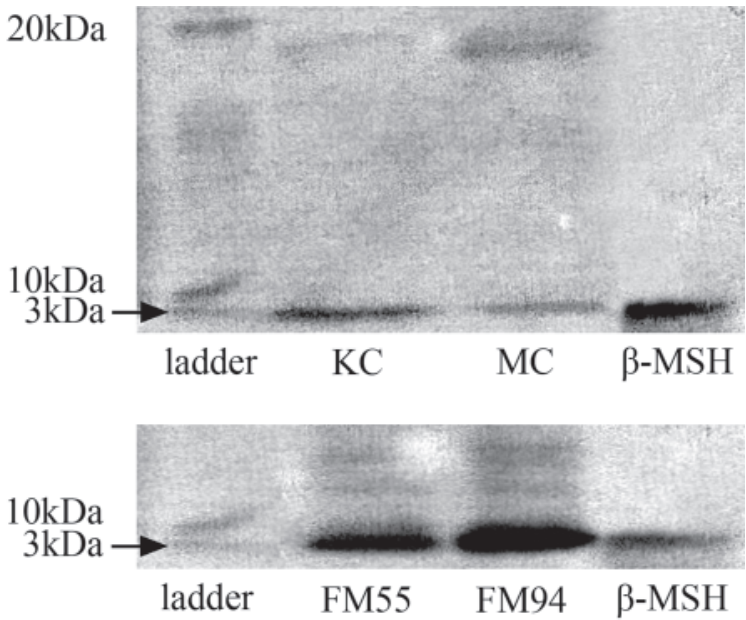

Figure 1 (A) $\beta-\mathrm{MSH}$ is expressed throughout the human epidermis. Co-localisation with $\mathrm{NKI} /$ beteb shows the presence of $\beta$-MSH in melanocytes along the stratum basale (i) DAPI, (ii) $\beta-\mathrm{MSH}$ (iii) $\mathrm{NKI} /$ beteb and (iv) $\beta-\mathrm{MSH}$ merged (magnification $\times 400$ ). (B) $\beta$-MSH expression within melanocytes derived from normal human skin phototype III (Fitzpatrick classification). (i) DAPI, (ii) $\beta$ - MSH,

(iii) $\beta$-MSH merged with NKI/beteb (magnification $\times 400$ ), (iv) insert of (iii) showing perinuclear co-localisation in a granular pattern.

(C) Immunogold labelling demonstrates the presence of $\beta-\mathrm{MSH}$ in all maturation stages. $\beta$-MSH-bound gold particles (arrows) are present in (A) early stage, lightly pigmented, (B) moderately pigmented and (C) heavily pigmented melanosomes in epidermal melanocytes of skin phototype IV (Fitzpatrick classification) (magnification $\times 100$ 000). (D) Western blot analysis confirms the presence of $\beta$-MSH in epidermal melanocytes and keratinocytes as well as in melanosomes. KC, keratinocytes; MC, melanocytes; FM55 and FM94, melanosomal preparation of human melanoma cells. $\beta-\mathrm{MSH}$ was used as a positive control.

sodium heptanesulphonate (Fluka Chemicals, Gillingham, Kent, UK) and $7 \cdot 5 \times 10^{-2} \mathrm{M}$ sodium dihydrogen orthophosphate dihydrate (Fisher Chemicals)) and snap frozen in liquid nitrogen according to the method of Said et al. (1990). Extracts were prepared in a micro-pestle and mortar as previously described and the supernatant de-proteinised by the addition of $5 \%(\mathrm{v} / \mathrm{v}) 2 \mathrm{~N}$ perchloric acid. Protein precipitates were removed by centrifugation and the supernatant was used for HPLC analysis.

All samples were analysed within $30 \mathrm{~min}$ of extraction. HPLC was conducted as described above. The mobile phase was methanol:heptanesulphonic acid buffer $(2 \cdot 5: 32$ $(\mathrm{v} / \mathrm{v}))$ and the flow rate was maintained at $1.0 \mathrm{ml} / \mathrm{min}$.
L-Dopa standards were prepared as $1 \mathrm{mM}$ stock solutions and L-tyrosine standards were prepared as $10 \mathrm{mM}$ stock solutions $\mathrm{pH}$ 9-2. Melanosomal extract $(100 \mu \mathrm{l})$ was injected per analysis with or without addition of standard. Analysis was carried out in duplicate of two different melanosomal preparations from FM55 and FM94 cells.

\section{Results}

$\beta-M S H$ is present in epidermal melanocytes and melanosomes Immunofluorescence demonstrated the presence of $\beta-\mathrm{MSH}$ throughout the human epidermis (Fig. 1A). 
Co-localisation of this peptide with the pre-melanosomal marker gp100 (NKI/beteb) indicated that $\beta-\mathrm{MSH}$ is present in the melanocyte (Fig. 1A,B). This was also demonstrated in cultured epidermal melanocytes (Fig. 1B). However, only some melanocytes yielded co-localisation, supporting the presence of cellular sub-populations even in situ. The granular pattern suggested expression within the melanosomes. In order to test this assumption, human epidermal melanocytes were examined with immunogold labelling and electron microscopy. The results showed the presence of $\beta-\mathrm{MSH}$ in melanosomes of all maturation stages (Fig. 1C). Western blot analysis confirmed the presence of $\beta-\mathrm{MSH}$ in keratinocytes and melanocytes as well as in melanosomes (Fig. 1D). The result also showed antibody specificity for $\beta$-MSH because the single band corresponded to the molecular weight of $\beta-\mathrm{MSH}$. There was no cross-reactivity observed with $\alpha-\mathrm{MSH}$ and $\beta$-lipotrophin. Moreover, $\beta$-MSH concentrations were determined in melanosomal extracts by radioimmunoassay following the manufacturer's protocol. The results yielded close to $10 \mathrm{pg} \beta-\mathrm{MSH} / \mathrm{mg}$ melanosomal protein.

\section{7-Biopterin is present in melanosomes}

Besides being a cofactor for the aromatic amino acid hydroxylases and the nitric oxide synthases, it was shown earlier that $6 \mathrm{BH}_{4}$ and $7 \mathrm{BH}_{4}$ could function as regulators of tyrosinase to control melanogenesis by allosteric inhibition (Wood et al. 1995). Since melanocytes have cytosolic PAH and $\mathrm{TH}$ activities while only $\mathrm{TH}$ and tyrosinase activities are present in the melanosomes, the presence of $7 \mathrm{BH}_{4}$ in these organelles was very likely. To test this assumption, melanosomal extracts from two different melanoma cell lines were subjected to acidic oxidation prior to analysis via HPLC using the standardised methods from Ziegler and Hültner (1992). Figure 2 shows the quantitative separation of a $100 \mu \mathrm{l}$ aliquot containing $1.35 \mathrm{mg}$ protein of oxidised melanosomal extract. Two suspect peaks were detected demonstrating the characteristic double peak of 6- and 7-biopterin. To confirm the identity of the compound a second aliquot was analysed upon addition of 5.8 pmoles 7-biopterin. The result confirmed that the suspected peak at $8.2 \mathrm{~min}$ was indeed 7 -biopterin. The amount was $4.2 \mathrm{pmol}$ of this pterin/1.35 mg melanosomal protein. There was no 6-biopterin detectable after spiking with this pteridine standard. The nature of the second peak needs to be assigned.

\section{Transport of $\left.{ }^{3} \mathrm{H}\right] 6 \mathrm{BH}_{4}$ into melanosomes}

Based on the above result, we decided to follow the possible melanosomal uptake of cytosolic $6 \mathrm{BH}_{4}$ since this is the essential precursor for the non-enzymatic formation of $7 \mathrm{BH}_{4}$. For this purpose we used ${ }^{3} \mathrm{H}-$ labelled $6 \mathrm{BH}_{4}$ and cold $6 \mathrm{BH}_{4}\left(10^{-4} \mathrm{M}\right)$ and studied the uptake over time in

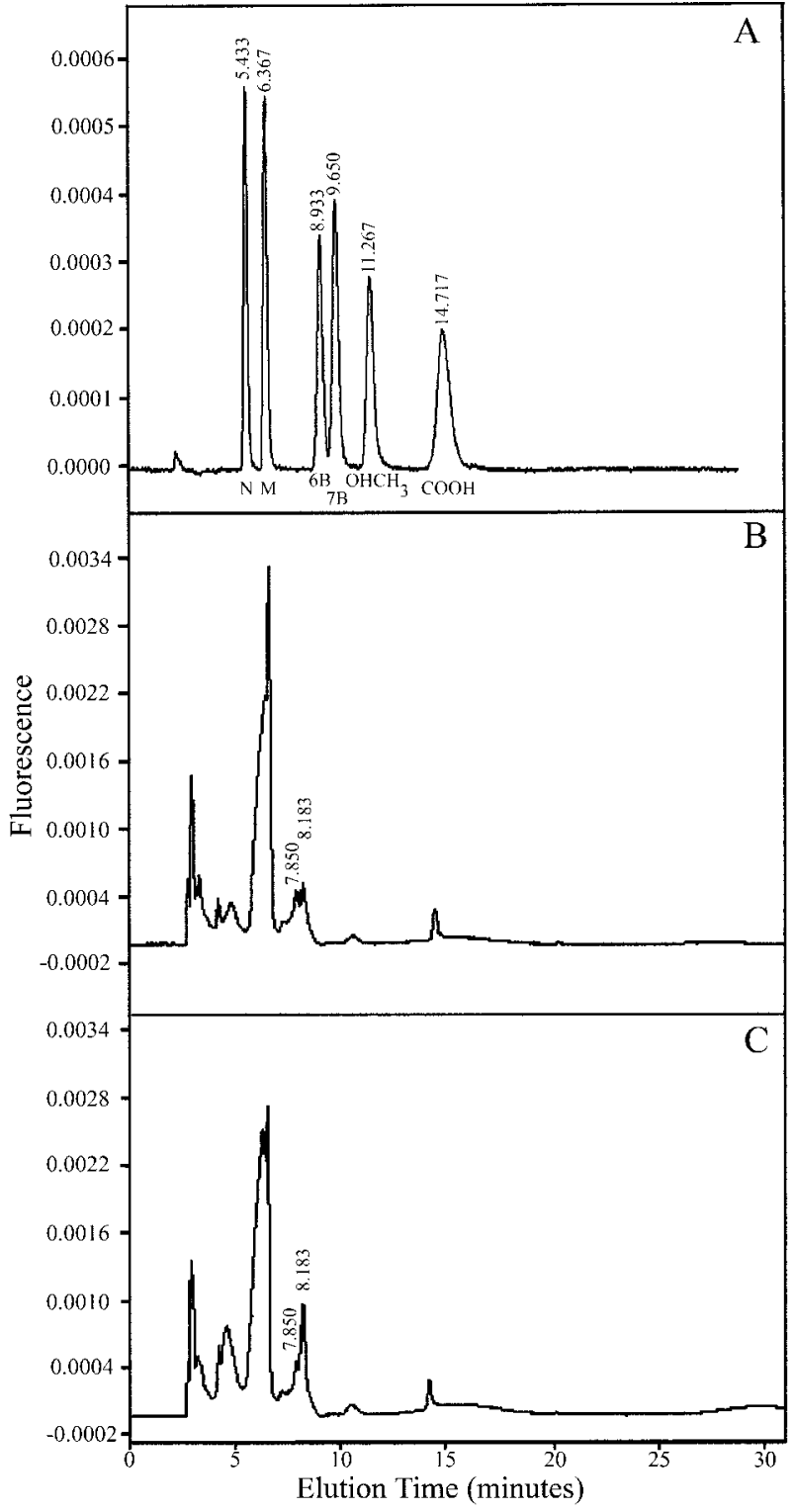

Figure 2 Identification of 7-biopterin in melanosomes. (A) HPLC of pterin standards (4 pmoles). $\mathrm{N}$, neopterin; $\mathrm{M}$, monapterin; $6 \mathrm{~B}$, 6-biopterin; 7B, 7-biopterin; $\mathrm{OHCH}_{2}$, 6-hydroxymethylpterin; $\mathrm{COOH}$, pterin-6-carboxylic acid. (B) Separation of a $100 \mu \mathrm{l}$ aliquot of melanosomal extract (1.35 mg protein). Suspected 6- and 7-biopterin peaks at $7 \cdot 8$ and $8 \cdot 2$ min respectively are indicated. (C) Confirmation of 7-biopterin after spiking with $5 \cdot 8$ pmoles 7-biopterin eluting at $8 \cdot 1 \mathrm{~min}$. Calculation of the 7 -biopterin concentration/1.35 mg melanosomal protein yielded $4 \cdot 2 \mathrm{pmol}$ which are equal to $33.6 \times 10^{-6} \mathrm{M}$.

melanosomal preparations. The results of these experiments proved a time-dependent uptake into these organelles. The

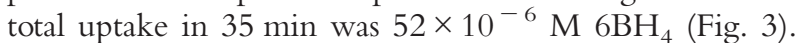
This slow uptake rate suggests facilitated diffusion rather than active transport of $6 \mathrm{BH}_{4}$ in melanosomes. 


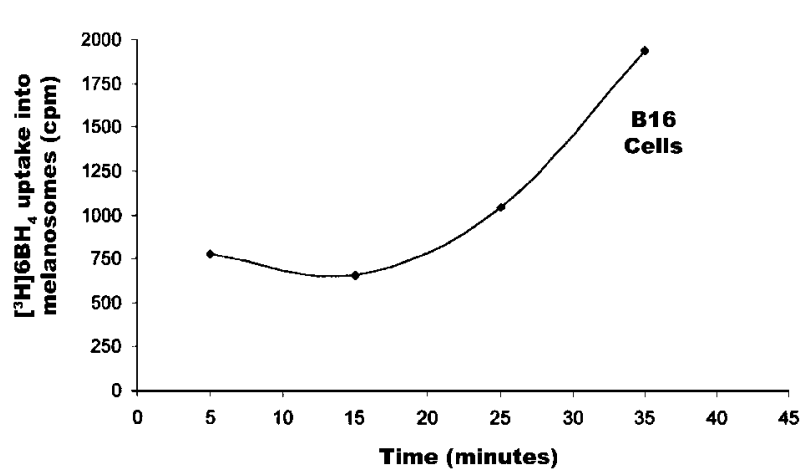

Figure $3\left[{ }^{3} \mathrm{H}\right] 6 \mathrm{BH}_{4}$ is taken up into purified melanosomes of B16 murine melanoma cells. Seventy-five microlitres $(1 \cdot 1 \mathrm{mg}$ protein) of intact melanosomal preparation were incubated over time with

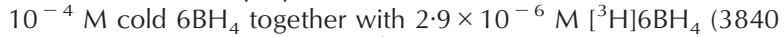

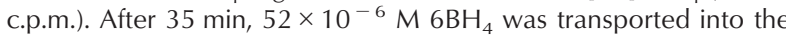
melanosomes. The values are the mean of duplicate experiments. The uptake is time dependent and indicates facilitated diffusion rather than active transport.

\section{Mixed allosteric inhibition of tyrosinase by $7 \mathrm{BH}_{4}$}

It has been well documented that under experimental in vitro conditions $6 \mathrm{BH}_{4}$ acts as an allosteric uncompetitive inhibitor of tyrosinase (Wood et al. 1995). Using Lineweaver-Burk plot analysis, we confirmed classical uncompetitive enzyme kinetics in the case of $6 \mathrm{BH}_{4}$ (Wood et al. 2004); meanwhile the 7-isomer acts via mixed inhibition kinetics (Fig. 4). This result suggests at least two alternative mechanisms for inhibition of tyrosinase by $7 \mathrm{BH}_{4}$, i.e. competitive and uncompetitive modes of action.

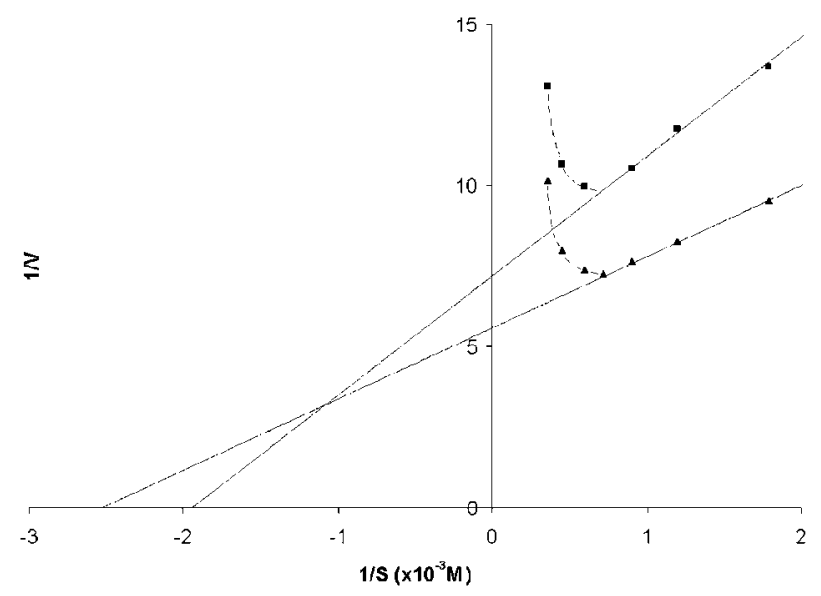

Figure 4 Lineweaver-Burk analysis of the inhibition of tyrosinase by $7 \mathrm{BH}_{4}$. Reactions contained $0-2 \cdot 78 \times 10^{-3}$ L-tyrosine $(\boldsymbol{\Delta})$, $30 \mu \mathrm{g}$ tyrosinase in phosphate buffer $(0 \cdot 1 \mathrm{M}) \mathrm{pH} 7 \cdot 4$ and $7 \mathrm{BH}_{4}$ $(117 \mu \mathrm{M})(\mathbf{\square})$. The inhibitor was always added last to the assay. Inhibitor concentrations were based on the 50\% inhibition rate of the enzyme as reported earlier (Wood et al. 1995). Tyrosinase is subject to substrate inhibition by L-tyrosine (dotted lines). Intersection of the lines indicates mixed inhibition.

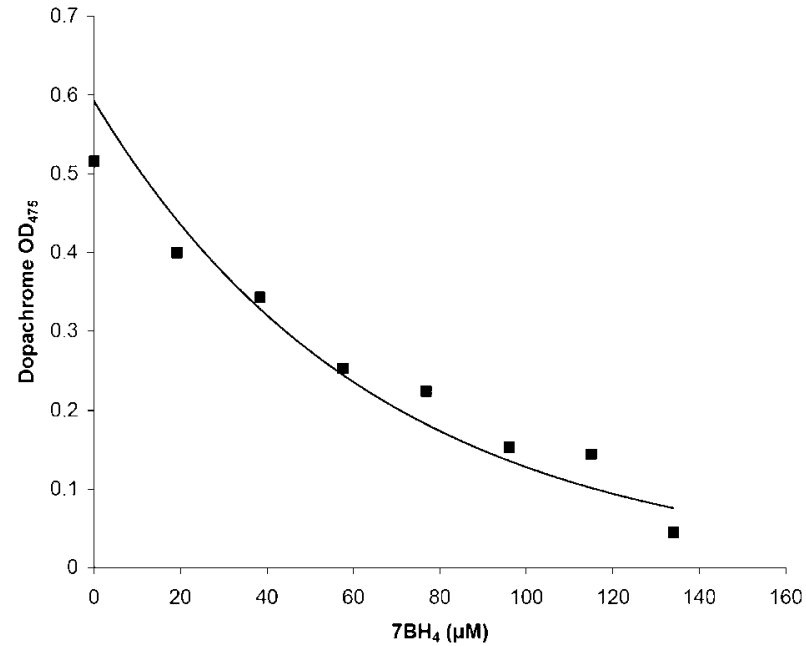

Figure 5 Dose-dependent reduction of dopachrome by $7 \mathrm{BH}_{4}$. All reactions were carried out in phosphate buffer $(0 \cdot 1 \mathrm{M}, \mathrm{pH} 7 \cdot 4)$ containing $1.0 \mathrm{mM}$ L-tyrosine and $30 \mu \mathrm{g}$ tyrosinase. The inhibitor $(0-134 \mu \mathrm{M})$ was always added last to the assay.

Dopachrome is reduced to L-dopa in the presence of $7 \mathrm{BH}_{4}$

To study the above finding in more detail, we decided to explore a possible competitive mechanism. Since it was shown recently that $6 \mathrm{BH}_{4}$ reduces dopachrome back to L-dopa, although at relatively high concentrations (Jung

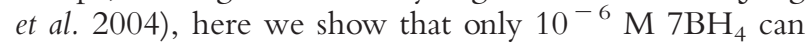
reduce dopachrome to L-dopa in a dose-dependent manner (Fig. 5). HPLC analysis confirmed the formation of $\mathrm{L}$-dopa during the standard tyrosinase reaction in the presence of $134 \mu \mathrm{M} 7 \mathrm{BH}_{4}$ which was the established optimum concentration for the reduction (Fig. 6).

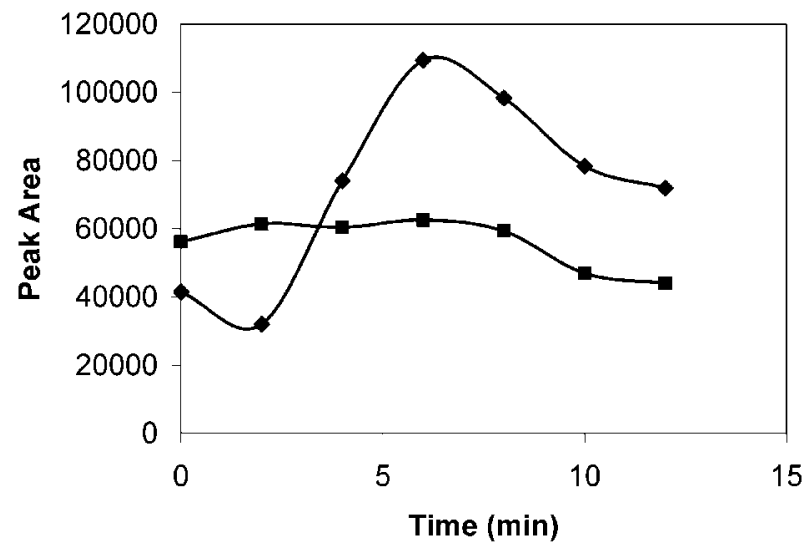

Figure 6 L-Dopa formation during inhibition of tyrosinase by $7 \mathrm{BH}_{4}$ (HPLC analysis). An increase in peak area over time yields the maximum reduction of dopachrome by $7 \mathrm{BH}_{4}$ back to $\mathrm{L}$-dopa after $5 \min (\bullet) .6 \mathrm{BH}_{4}$ does not produce L-dopa ( $\left.\mathbf{\square}\right)$. Since L-dopa is an intermediate in the reaction pathway from L-tyrosine, this result explains the competitive component of the mixed kinetics in Fig. 4. 


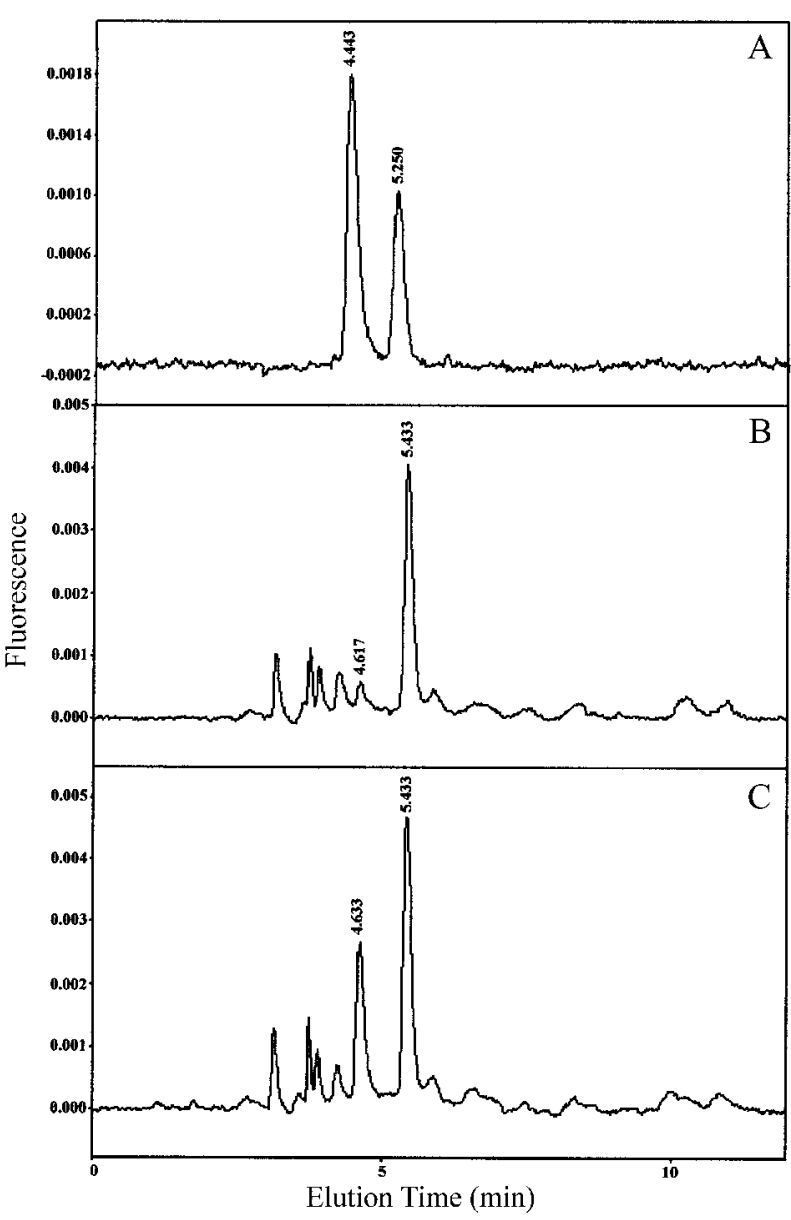

Figure 7 HPLC analysis identifies the presence of L-dopa in melanosomes. (A) HPLC of L-tyrosine and L-dopa standards (50 pmoles). (B) Separation of a $120 \mu$ aliquot ( $13.5 \mathrm{mg}$ protein) of melanosomal extract. Suspected L-dopa and L-tyrosine eluted at 4.6 and 5.4 min respectively. (C) Separation of a $120 \mu \mathrm{l}$ aliquot (13.5 mg protein) of melanosomal extract spiked with $60 \mathrm{pmol}$ L-dopa confirming the identity of the peak at $4.6 \mathrm{~min}$.

However, the natural co-factor $6 \mathrm{BH}_{4}$ was unable to have the same effect at this concentration. HPLC analysis of melanosomal extracts demonstrated that L-dopa is indeed present in human melanosomes. L-Dopa elutes under these conditions with a peak at 4.6 min, together with an L-tyrosine peak at $5.4 \mathrm{~min}$ (Fig. 7). This result proves a competitive mechanism involving the reduction of dopachrome back to L-dopa thus explaining the observed mixed kinetics shown in Fig. 4.

Reactivation of the tyrosinase $7 \mathrm{BH}_{4}$ inhibitor complex by $\beta$-MSH

As shown earlier, both $\alpha-$ and $\beta-\mathrm{MSH}$ can reactivate the $6 \mathrm{BH}_{4} /$ tyrosinase inhibitor complex by binding to the pterin (Marles et al. 2002). Figure 8 demonstrates that $\beta-\mathrm{MSH}$ reactivates the $7 \mathrm{BH}_{4}$ inhibited tyrosinase

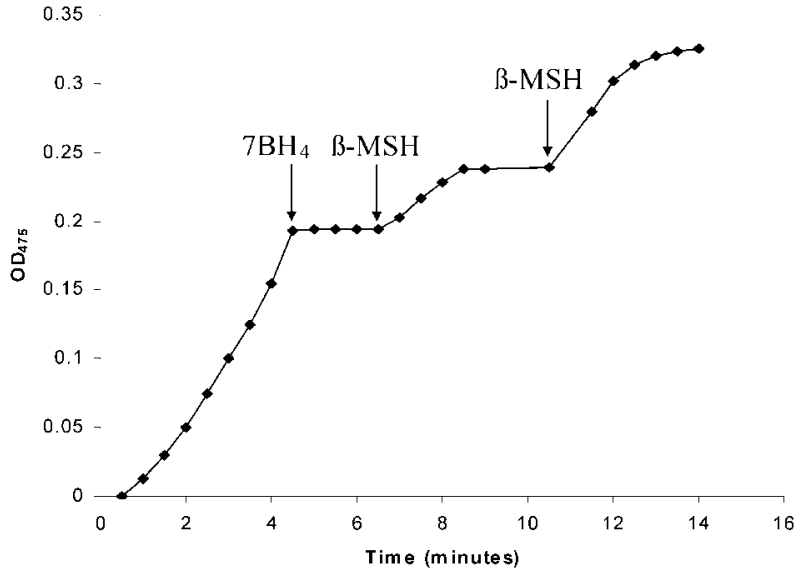

Figure 8 Reactivation of $7 \mathrm{BH}_{4}$ inhibited tyrosinase by $\beta-\mathrm{MSH}$. Reaction mixture contained $0 \cdot 1 \mathrm{M}$ phosphate buffer $(\mathrm{pH} 7 \cdot 4)$, $1.0 \mathrm{mM}$ tyrosine and $30 \mu \mathrm{g}$ tyrosinase. Upon the addition of $7 \mathrm{BH}_{4}$ at $4.5 \mathrm{~min}$, tyrosinase was completely inhibited. Reactivation was achieved upon sequential addition of $\beta$-MSH $(10 \mu \mathrm{M})$ at $6.5 \mathrm{~min}$ and at $10.5 \mathrm{~min}$.

in a dose-dependent manner. Earlier, it was shown that $\alpha-\mathrm{MSH}$ has no effect on this inhibitor complex (Schallreuter et al. 1999).

\section{Discussion}

This study demonstrates that melanosomes in human melanocytes have the capacity to produce $\beta-\mathrm{MSH}$ (Peters et al. 2000, Kauser et al. 2005) besides the production of $\alpha-\mathrm{MSH}, \mathrm{ACTH}$ and $\beta$-endorphin. Moreover, $7 \mathrm{BH}_{4}$, the non-enzymatic isomer of the important cofactor $6 \mathrm{BH}_{4}$ is present in these organelles. We provide evidence that these $7 \mathrm{BH}_{4}$ concentrations are sufficient to regulate tyrosinase by two alternative mechanisms. We have shown uncompetitive inhibition of tyrosinase by $7 \mathrm{BH}_{4}$ and competitive inhibition of the enzyme by this pteridine leading to reduction of dopachrome to L-dopa (Figs 4 and 5). The tyrosinase inhibitor complex can be reactivated in the presence of $\beta-\mathrm{MSH}$ but not by $\alpha-\mathrm{MSH}$. Therefore, it can be concluded that both mechanisms depend on the concentration of $7 \mathrm{BH}_{4}$ and $\beta-\mathrm{MSH}$ in the melanosome.

Since $7 \mathrm{BH}_{4}$ is a much more potent inhibitor of tyrosinase compared with $6 \mathrm{BH}_{4}$, these results suggest, for the first time, a physiological function for this isomer. However, it must be noted that the presence of $7 \mathrm{BH}_{4}$ in melanosomes also implicates $6 \mathrm{BH}_{4}$ in this organelle, since the 7-isomer is only produced by the aromatic amino acid hydroxylases from $6 \mathrm{BH}_{4}$ via $4 \mathrm{a}-\mathrm{OH}$-carbinolamine in the absence of PCD (Curtius et al. 1990a, Davis et al. 1991, Adler et al. 1992). It is noteworthy that the presence of tyrosine hydroxylase isoform I (TH) has been demonstrated in melanosomes while PAH is absent in this organelle (Marles et al. 2003). Whether the third hydroxylase, i.e. 
tryptophan hydroxylase, is present remains to be shown. HPLC analysis of the oxidised melanosomal extract detected only 7-biopterin. However, in this study we present evidence that ${ }^{3} \mathrm{H}$-labelled $6 \mathrm{BH}_{4}$ transport occurs into melanosomes (Fig. 3). Given the above circumstances, it is tempting to conclude that the 7-isomer originates from the $\mathrm{TH}$ reaction after uptake of cytosolic $6 \mathrm{BH}_{4}$ into melanosomes. In this context it is important to recognise that $\mathrm{TH}$ does require $6 \mathrm{BH}_{4}$ while $7 \mathrm{BH}_{4}$ fails to act as a co-factor or inhibitor for this reaction (Davis et al. 1992). Our results demonstrated that $7 \mathrm{BH}_{4}$ is a potent inhibitor of tyrosinase with mixed inhibition kinetics (Fig. 4) and that this inhibitor complex is under specific regulation by $\beta-\mathrm{MSH}$ (Fig. 8). Importantly, the presence of $7 \mathrm{BH}_{4}$ in the $10^{-6} \mathrm{M}$ range in the melanosomes is also a potential source for L-dopa formation from dopachrome (Fig. 5). Since L-dopa is required as an electron donor for the activation of the two $\mathrm{Cu}^{\mathrm{II}}$ centres in tyrosinase (Prota 1992) and considering that the $\mathrm{pH}$ optimum for tyrosinase is $7 \cdot 4$, the above mechanism could provide an additional source for L-dopa formation in melanosomes to foster dopachrome oxidase activity of tyrosinase (Wood et al. 1995).

Previous work on the upregulation of tyrosinase activities and melanin synthesis in cultured melanocytes by $\beta-\mathrm{MSH}$ indicated that this POMC peptide was implicated in the regulation of melanogenesis (McLane \& Pawelek 1988, Chakraborty et al. 1991, Pawelek et al. 1992). However, the mechanism of action remained unknown. The presence of $\beta-\mathrm{MSH}$ in human melanosomes is not surprising since the entire POMC machinery has previously been demonstrated in these organelles (Peters et al. 2000, Kauser et al. 2003, 2005).

The results of the study presented herein could call into question the regulation of tyrosinase by $6 \mathrm{BH}_{4} / \alpha$ - and $\beta-\mathrm{MSH}$ as proposed earlier by our group, despite the fact that $\alpha-\mathrm{MSH}$ and its function as an activator of the $6 \mathrm{BH}_{4} /$ tyrosinase inhibitor complex was well documented under the experimental conditions used in those studies (Wood et al. 1995, Schallreuter et al. 1998, 1999, Moore et al. 1999, Marles 2002). Since we showed uptake of cytosolic ${ }^{3}[\mathrm{H}] 6 \mathrm{BH}_{4}$ into melanosomes by facilitated diffusion, but only found its product $7 \mathrm{BH}_{4}$ in this organelle, the question remains as to whether $6 \mathrm{BH}_{4}$ can indeed regulate tyrosinase in the melanosome.

In summary, based on our results we propose a novel receptor-independent function for the melanocortin $\beta-\mathrm{MSH}$ in the regulation of tyrosinase. In support of this mechanism it has been shown that $\beta-\mathrm{MSH}$ is a very weak agonist for the MC1-R with a $K_{\mathrm{D}} 10$-fold higher than a-MSH (Suzuki et al. 1996, Wikberg 1999). Moreover, due to concentration-dependent mixed inhibition kinetics by $7 \mathrm{BH}_{4}$ we propose that this pteridine can exercise two physiological functions in the regulation of tyrosinase. This hypothesis is supported by the concentrations of $\beta-\mathrm{MSH}$, L-dopa and $7 \mathrm{BH}_{4}$ found in melanosomes.

\section{Acknowledgements}

This work was generously supported by Stiefel International by a grant to K U S. The results are part of a $\mathrm{PhD}$ thesis by J D S. The work is original and has not been and will not be submitted for publication elsewhere. There is no conflict of interest that would prejudice its impartiality.

\section{References}

Abdel-Malek Z, Swope VB, Suzuki I, Akcali C, Harriger MD, Boyce ST, Urabe K \& Hearing VJ 1995 Mitogenic and melanogenic stimulation of normal human melanocytes by melanotropic peptides. PNAS 92 1789-1793.

Adler C, Ghisla S, Rebrin I, Haavik J, Heizmann CW, Blau N, Kuster T \& Curtius HC 1992 7-Substituted pterins in humans with suspected pterin-4a-carbinolamine dehydratase deficiency. Mechanism of formation via non-enzymatic transformation from 6-substituted pterins. European Journal of Biochemistry 208 139-144.

Chakraborty AK, Orlow SJ, Bolognia JL \& Pawelek JM 1991 Structural/functional relationships between internal and external MSH receptors: modulation of expression in Cloudman melanoma cells by UVB radiation. Journal of Cell Physiology 147 1-6.

Curtius HC, Kuster T, Matasovic A, Blau N \& Dhondt JL 1988 Primapterin, anapterin, and 6-oxo-primapterin, three new 7-substituted pterins identified in a patient with hyperphenylalaninemia. Biochemical and Biophysical Research Communications 153 715-721.

Curtius HC, Adler C, Rebrin I, Heizmann C \& Ghisla S 1990a 7-Substituted pterins: formation during phenylalanine hydroxylation in the absence of dehydratase. Biochemical and Biophysical Research Communications 172 1060-1066.

Curtius HC, Matasovic A, Schoedon G, Kuster T, Guibaud P, Giudici T \& Blau N 19906 7-Substituted pterins. A new class of mammalian pteridines. Journal of Biological Chemistry 265 3923-3930.

Davis MD \& Kaufman S 1991 7-Tetrahydrobiopterin is an uncoupled cofactor for rat hepatic phenylalanine hydroxylase. FEBS Letters 285 $17-20$.

Davis MD, Kaufman S \& Milstien S 1991 Conversion of 6-substituted tetrahydropterins to 7 -isomers via phenylalanine hydroxylasegenerated intermediates. PNAS 88 385-389.

Davis MD, Ribeiro P, Tipper J \& Kaufman S 1992 '7-Tetrahydrobiopterin,' a naturally occurring analogue of tetrahydrobiopterin, is a cofactor for and a potential inhibitor of the aromatic amino acid hydroxylases. PNAS 89 10109-10113.

Fitzpatrick TB, Miyamoto M \& Ishikawa K 1967 The evolution of concepts of melanin biology. Archives of Dermatology 96 305-323.

Geschwind II, Huseby RA \& Nishioka R 1972 The effect of melanocyte-stimulating hormone on coat color in the mouse. Recent Progress in Hormone Research 28 91-130.

Hunt G, Donatien PD, Lunec J, Todd C, Kyne S \& Thody AJ 1994 Cultured human melanocytes respond to MSH peptides and ACTH. Pigment Cell Research 7 217-221.

Jung JH, Choi SW \& Han S 2004 Indirect oxidation of 6-tetrahydrobiopterin by tyrosinase. Biochemical and Biophysical Research Communications 314 937-942.

Kalb VF Jr \& Bernlohr RW 1977 A new spectrophotometric assay for protein in cell extracts. Analytical Biochemistry 82 362-371.

Kauser S, Schallreuter KU, Thody AJ, Gummer C \& Tobin DJ 2003 Regulation of human epidermal melanocyte biology by beta-endorphin. Journal of Investigative Dermatology 120 1073-1080.

Kauser S, Thody AJ, Schallreuter KU, Gummer CL \& Tobin DJ 2005 A fully functional proopiomelanocortin/melanocortin-1 receptor system regulates the differentiation of human scalp hair follicle melanocytes. Endocrinology 146 532-543. 
Kiistala U \& Mustakallio KK 1964 In vivo separation of epidermis by production of suction blisters. Lancet 41 1444-1445.

Lerner AB \& McGuire JS 1961 Effect of alpha- and beta-melanocytestimulating hormones on the skin colour of man. Nature 189 176-179.

Lerner AB \& McGuire JS 1964 Melanocyte-stimulating hormone and adrenocorticotrophic hormone. Their relation to pigmentation. New England Journal of Medicine 270 539-546.

McLane JA \& Pawelek JM 1988 Receptors for $\beta$-melanocytestimulating hormone exhibit positive cooperativity in synchronized melanoma cells. Biochemistry 27 3743-3747.

Marles LK 2002 Epidermal Tyrosine Hydroxylase: Is There a Role in Pigmentation? PhD Thesis, University of Bradford, UK.

Marles LK, Khalil A, Gibbons NCJ \& Schallreuter KU 2002 The regulation of tyrosinase and tyrosine hydroxylase activities by alphaand beta-MSH. Pigment Cell Research 1559.

Marles LK, Peters EM, Tobin DJ, Hibberts NA \& Schallreuter KU 2003 Tyrosine hydroxylase isoenzyme I is present in human melanosomes: a possible novel function in pigmentation. Experimental Dermatology 12 61-70.

Moore J, Wood JM \& Schallreuter KU 1999 Evidence for specific complex formation between alpha-melanocyte stimulating hormone and $6(\mathrm{R})$-L-erythro-5,6,7,8-tetrahydrobiopterin using near infrared Fourier transform Raman spectroscopy. Biochemistry $\mathbf{3 8}$ 15317-15324.

Pawelek JM, Chakraborty AK, Osber MP, Orlow SJ, Min KK, Rosenzweig KE \& Bolognia JL 1992 Molecular cascades in UV-induced melanogenesis: a central role for melanotropins? Pigment Cell Research 5 348-356.

Peters EM, Tobin DJ, Seidah NG \& Schallreuter KU 2000 Pro-opiomelanocortin-related peptides, prohormone convertases 1 and 2 and the regulatory peptide 7B2 are present in melanosomes of human melanocytes. Journal of Investigative Dermatology 114 430-437.

Prota G 1992 The role of peroxidase in melanogenesis revisited. Pigment Cell Research Suppl 2 25-31.

Said R, Robinet D, Barbier C, Sartre J \& Huguet C 1990 Fully automated high-performance liquid chromatographic assay for the analysis of free catecholamines in urine. Journal of Chromatography $\mathbf{5 3 0} 11-18$.

Schallreuter KU, Wood JM, Ziegler I, Lemke KR, Pittelkow MR, Lindsey NJ \& Gütlich M $1994 a$ Defective tetrahydrobiopterin and catecholamine biosynthesis in the depigmentation disorder vitiligo. Biochimica et Biophysica Acta 1226 181-192.

Schallreuter KU, Wood JM, Pittelkow MR, Gütlich M, Lemke KR, Rödl W, Swanson NN, Hitzemann K \& Ziegler I $1994 b$ Regulation of melanin biosynthesis in the human epidermis by tetrahydrobiopterin. Science 263 1444-1446.
Schallreuter K, Slominski A, Pawelek JM, Jimbow K \& Gilchrest BA 1998 What controls melanogenesis? Experimental Dermatology 7 143-150.

Schallreuter KU, Moore J, Tobin DJ, Gibbons NJ, Marshall HS, Jenner T, Beazley WD \& Wood JM 1999 Alpha-MSH can control the essential cofactor 6-tetrahydrobiopterin in melanogenesis. Annals of the New York Academy of Sciences 885 329-341.

Schallreuter KU, Moore J, Wood JM, Beazley WD, Peters EM, Marles LK, Behrens-Williams SC, Dummer R, Blau N \& Thöny B 2001 Epidermal $\mathrm{H}_{2} \mathrm{O}_{2}$ accumulation alters tetrahydrobiopterin $\left(6 \mathrm{BH}_{4}\right)$ recycling in vitiligo: identification of a general mechanism in the regulation of all $6 \mathrm{BH}_{4}$-dependent processes? Journal of Investigative Dermatology 116 167-174.

Seiji M, Fitzpatrick TB \& Birbeck MS 1961 The melanosome: a distinctive subcellular particle of mammalian melanocytes and the site of melanogenesis. Journal of Investigative Dermatology 36 243-252.

Suzuki I, Cone RD, Im S, Nordlund J \& Abdel-Malek ZA 1996 Binding of melanotropic hormones to the melanocortin receptor MC1R on human melanocytes stimulates proliferation and melanogenesis. Endocrinology 137 1627-1633.

Thody AJ, Ridley K, Penny RJ, Chalmers R, Fisher C \& Shuster S 1983 MSH peptides are present in mammalian skin. Peptides 4 813-816.

Thöny B, Auerbach G \& Blau N 2000 Tetrahydrobiopterin biosynthesis, regeneration and functions. Biochemical Journal 347 $1-16$.

Tsatmali M, Yukitake J \& Thody AJ 1999 ACTH1-17 is a more potent agonist at the human MC1 receptor than alpha-MSH. Cellular and Molecular Biology 45 1029-1034.

Tsatmali M, Ancans J, Yukitake J \& Thody AJ 2000 Skin POMC peptides: their actions at the human $\mathrm{MC}-1$ receptor and roles in the tanning response. Pigment Cell Research 13 Suppl 8 125-129.

Wikberg JE 1999 Melanocortin receptors: perspectives for novel drugs. European Journal of Pharmacology 375 295-310.

Wood JM, Schallreuter-Wood KU, Lindsey NJ, Callaghan S \& Gardner ML 1995 A specific tetrahydrobiopterin binding domain on tyrosinase controls melanogenesis. Biochemical and Biophysical Research Communications 206 480-485.

Wood JM, Chavan B, Hafeez I \& Schallreuter KU 2004 Regulation of tyrosinase by tetrahydropteridines and $\mathrm{H}_{2} \mathrm{O}_{2}$. Biochemical and Biophysical Research Communications 325 1412-1417.

Ziegler I \& Hültner L 1992 Tetrahydro-6-biopterin is associated with tetrahydro-7-biopterin in primary murine mast cells. FEBS Letters 307 147-150.

Received 6 July 2005

Accepted 15 August 2005 